\title{
A Comparative Study and Analysis on Conventional Solar PV Based DC-DC Converters and MPPT Techniques
}

\author{
M. Premkumar, K. Karthick, R. Sowmya \\ GMR Institute of Technology, GMR Nagar, Rajam, Andhra Pradesh, 532127, India
}

\begin{tabular}{ll}
\hline \hline Article Info & ABSTRACT \\
\cline { 2 - 3 } Article history: & $\begin{array}{l}\text { As electricity demand escalated with supply, though there are lot of thermal } \\
\text { power station, nuclear energy and other conventional power sources. Yet, } \\
\text { there is exhaustion in the above assets and adding dangerous impacts to the } \\
\text { Received Nov 25, } 2017\end{array}$ \\
atmospheric conditions. The world searches for sustainable power source that \\
it is normally accessible such as sun and wind. Apart from all the renewable \\
energy resources, solar energy is readily harnessed for domestic application \\
to meet demand. To increase the power conversion efficiency from the solar \\
Keywords: & $\begin{array}{l}\text { PV system it is better have a perfect DC to DC converters. The proposed } \\
\text { outcome of this paper is to outline the DC to DC converter with MPPT } \\
\text { algorithms to concentrate on extreme productivity at roof-top for solar PV }\end{array}$ \\
Control techniques & application which decreases the cost of energy. In addition to that it also \\
prevents panel miss matching at all environmental conditions for safer DC \\
MATLAB model \\
Voltage with flexible site design especially for domestic applications from \\
the solar photovoltaic module. It is necessary to analyze the converters and \\
MPPT algorithms \\
of solar PV system to the load or to the grid. This review summarizes few \\
DC to DC converter topologies, maximum power point tracking algorithm \\
and also paid attention on the advantages and disadvantages of these \\
algorithms and topologies.
\end{tabular}

Copyright (c) 2018 Institute of Advanced Engineering and Science. All rights reserved.

Corresponding Author:

M. Premkumar,

GMR Institute of Technology,

GMR Nagar, Rajam, Andhra Pradesh, 532127, India.

Email: mprem.me@g mail.com

\section{INTRODUCTION}

The main component in the solar power generation is the solar cell. The group of solar cells together forms a PV panel. The term PV refers to Photovoltaic system used for the solar power generation. Thus, the group of PV panels forms a solar PV array. The solar power generation happens by converting the solar irradiation (photons) into the electrical energy by using the basic semiconductor device (i.e. photodiode). Hence, the basic unit of solar power generation is the solar cell, where the solar irradiation is directly converted into the electricity without any intermediate process. The photodiode can be said as semiconductor device which proselytes light into current. The sun powered cell create power while the light strikes on it and the voltage or potential will built up over the terminals of the cell and settled to $0.5 \mathrm{~V}$. The curren t capacity of cell is nearly proportional to the intensity of incident light as well as the area that exposed to the light. A semiconductor $\mathrm{p}-\mathrm{n}$ junction is in the middle of negative front contact and positive back end contacts. The gathering of light carriers causes the development of electrons. A photovoltaic technology is used in the photovoltaic cells. There are different photovoltaic materials that are available in the market. The most common materials are mono-crystalline, poly-crystalline and thin film technology. The general block diagram of the solar PV system is shown in Figure 1. The equivalent circuit of solar PV module is shown in Figure 2 . 


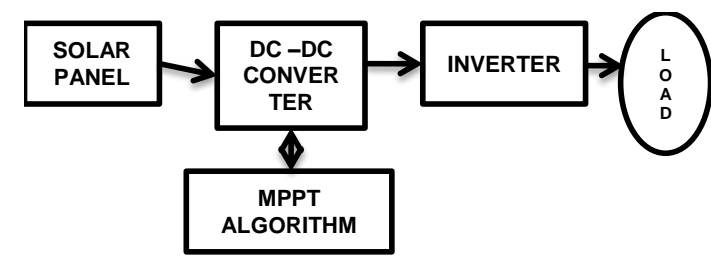

Figure 1. Block diagram of solar PV systems

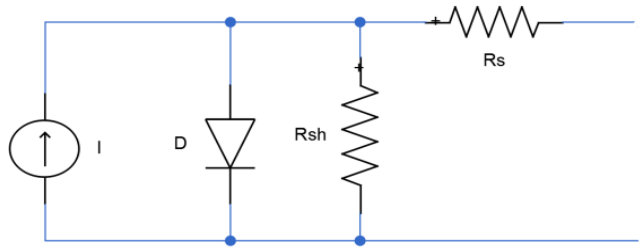

Figure 2. Equivalent cell diagram of PV panel

The characteristic equation [1] of the solar PV cell shown in the Equation 1 and 2.

$$
I=I_{l g}-I_{o s} \times\left[\exp \left(q \times \frac{V+I \times R s}{A \times K \times T}\right)-1\right]-\frac{V+I \times R s}{R s h}
$$

Also,

$$
I_{l g}=\left\{I_{s c r}+K i \times(T-25)\right\} \times S
$$

where, $\mathrm{I}=$ Cell output current (Amperes), V=cell output voltage (in volts), $\mathrm{I}_{\mathrm{lg}}=$ light generated current (Amperes), $\quad \mathrm{I}_{\mathrm{os}}=$ Reverse saturation current(Amperes), $\mathrm{R}_{\mathrm{sh}=\text { Shunt }}$ resistance(ohms), $\mathrm{R}_{\mathrm{s}}=$ series resistance(ohms), $\mathrm{S}=$ solar radiation $\left(\mathrm{W} / \mathrm{m}^{2}\right), \mathrm{q}=$ Electron charge $\left(1.602 * 10^{-19}\right.$ Coulomb), $\mathrm{N}=\mathrm{Ideality}$ factor of the diode, $\mathrm{K}=$ Boltzmann's constant $\left(1.381 * 10^{-23} \mathrm{~J} / \mathrm{K}\right), \mathrm{T}=\mathrm{Junction}$ temperature(Kelvin), $\mathrm{K}_{\mathrm{i}=\mathrm{short}}$ circuit current temperature coefficient.

The most common topology for the power converter design is string inverter and centralize d inverter for solar PV application. The major drawbacks of the solar PV system are PV panel mismatch losses and shadow losses in the solar PV system [2]. The shaded panel output reduces the unshaded panel output as the circulating flows through the system [3]. To avoid this type of losses the individual solar PV module is connected to one MPPT converters. This type of technique is called Distributed MPPT (DMPPT) [4-5]. To attain the maximum efficiency the MPPT algorithms, DC to DC Converter topologies and proper synchronization are required in the solar PV system.

For renewable energy sources, the power electronics converters act as the interfacing components in connecting the source to the load or to the grid facing difficult issues. This is utilized to en hance the power and frequency control and increase the reliability of the system while connecting to the grid. This also paper reveals different power DC to DC converter topologies and various MPPT algorithms to attain maximum efficiency.

Apart from the power converter topologies, it is required to connect the solar PV panel output to load by proper synchronization. This involves how to configure the topologies by employing closed loop control and proper connections to avoid the circulating current flow through the circuit. In the chapter V, the detailed description of how the PV module is connected to the grid is discussed.

\section{DC TO DC CONVERTER}

The DC to DC converters are used to give variable output into the constant output voltage or tracking the more power from the PV system using MPPT technique. For MPPT, it is necessary to match the input resistance of the panel with the load resistance (by varying the duty cycle), and that is required for a DC to DC converter. The DC to DC converters can be used to convert an unregulated dc voltage to a regulated dc output voltage. With PWM (Pulse Width Modulation) techniques, the regulation is achieved at a fixed frequency to achieve the output voltage. Generally, the switching devices are BJT, MOSFET or IGBT used for conversion. A DC to DC converter is a component that accepts a DC input voltage and produces a required DC output voltage. In addition to that, the converters are used to provide isolation and voltage regulation when connecting the customer load from the renewable energy sources. There are different popular DC to DC converter topologies that are available in the market [6].

The duty cycle is defined as the ratio of ON time (Ton) period to total time period $(\mathrm{T})$. There are several approaches to design a DC to DC converter, to achieve the desired voltage when the input varies. The output varied can be increased, decreased and varied based on the topology employed. As the yield from the solar PV panel is shifting in nature that could not satisfy the load requirement. Thus, the study for three converters namely buck, boost and buck boost converter is shown in Figure 3. The efficiency of these converters is compared using the graph. 


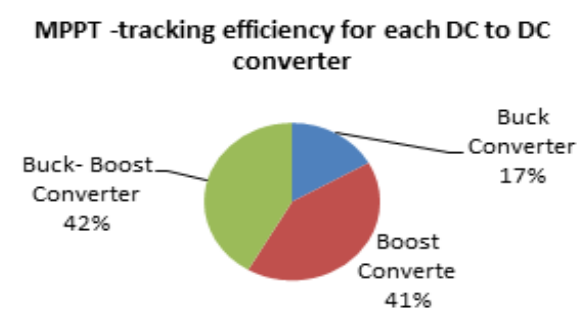

Figure 3. Comparison of converter based on MPPT

\subsection{Buck Converter}

The buck converter is shown in Figure 4 is utilized to convert the high voltage of the solar panel to the low voltage at the output. Suppose the panel voltage is greater than the expected it may cause some problem for the entire system which leads to overvoltage. This type of losses in the system is reduced by using suitable converter. The configuration of buck converter for ON state and OFF state is described by using switches. The output voltage equation for buck converter based on the duty cycle is,

$$
V_{\text {out }}=D V_{\text {in }}
$$

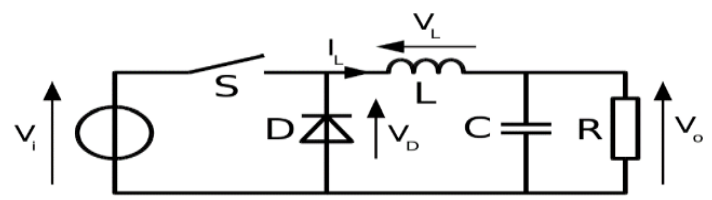

Figure 4. Circuit diagram for buck converter

Buck converters are highly efficient in converting input voltage to a lower required voltage. The buck converter contains current through inductor controlled by two switches where they have zero voltage drop when on and zero current drop when off. Inductor should have zero series resistance. Finally, the input voltage shouldn't be changed to have a constant output voltage.

When the current through inductor never falls to zero during commutation cycle it occurs in continuous conduction mode. When switch is closed then the path existence will be as shown in figure. During this period the inductor current gets increased gradually. As the diode is reverse biased the curren $t$ doesn't flow through it. Energy stored in inductor increases gradually during switch on as the current is getting increased. Inductor is used to transfer energy from input to output of the converter. When the switch is open then the path will be as shown in Figure 5. The current through the inductor gets reduced gradually during this period. The energy stored in inductor also gets reduced. The switching period is decided by the duty cycle which is the ratio of on time to total time of the commutation cycle.

\subsection{Boost Converter}

Boost converter is shown Figure 5 is used to boost up the input voltage based on the duty cycle according to the required output voltage. The configuration of boost converter for $\mathrm{ON}$ state and OFF state is described below by using switches. The output voltage equation for boost converter based on the duty cycle is,

$$
V_{\text {out }}=\frac{1}{1-D} V_{\text {in }}
$$

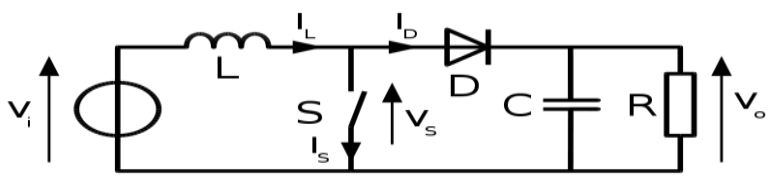

Figure 5. Circuit diagram for boost converter 
The current through inductor increases when the switch is in on state. As the circuit gets short circuited, the energy through inductor increased and when the switch is open, the current will be reduced as the impedance is higher. The continuous mode takes place when the current through inductor never falls to zero. When the current through inductor becomes zero then that will be considered to be dis continuous mode. When the switch is on, the input voltage will be appeared across inductor and current through the load is zero. When the switch is off, there the input current flows through the load. The input current is same as inductor current. The capacitor at the load side is used to filter the ripples for output voltage.

\subsection{Buck-Boost Converter}

The buck converter is used to convert the higher voltage value in to the lower voltage and vice-versa from the solar panel. The configuration of buck-boost converter as shown in Figure 6 for ON state and OFF state is described below by using switches.

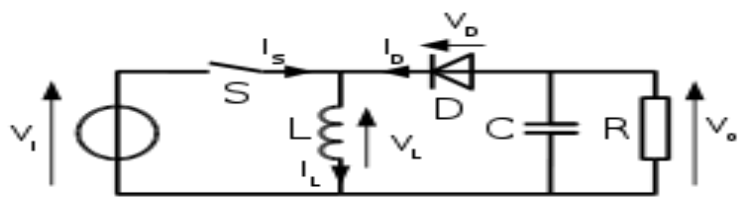

Figure 6. Circuit diagram for buck-boost converter

The output voltage equation for buck-boost converter based on the duty cycle is;

$$
V_{\text {out }}=\frac{D}{1-D} V_{\text {in }}
$$

Where, $\mathrm{V}_{\text {out }}=$ Output Voltage, $\mathrm{V}_{\text {in }}=$ Input Voltage.

When the switch is in on state, the input voltage is directly connected to the inductor. This results in increase of energy through inductor. The capacitor at the output side supplies energy to the load. As the capacitor discharges in inverting mode the voltage across the output is in opposite polarity of input voltage. When the switch in off state, the input voltage will be appeared across the mosfet switch. The inductor charged during the switch on period gets discharged when the switch is in off state. During this period the capacitor gets charged and this process gets repeated.

The hardware-based comparison of buck-boost converter topologies with other topologies such as SEPIC and CUK is shown in the table below. The Table 1 result shows that the MPPT capability is perfect for all the converters and the fluctuations is higher for the isolated converter topology compare d to the nonis olated topology.

\begin{tabular}{cccc} 
Table 1. Comparis on of Buck-Boost Converter with Other Topologies \\
\hline Specification & Buck-Boost & SEPIC & CUK \\
\hline MPPT Capability & Perfect & Perfect & Perfect \\
No of Component & Low & High & High \\
Control Requirement & Isolated & Non-isolated & Non-isolated \\
Current Measurement & Hard & Easy & Easy \\
Fluctuations & High & Medium & Low \\
Tracking Efficiency & Low & Medium & High \\
\hline
\end{tabular}

\section{MAXIMUM POWER POINT TRACKING}

The key optimizer of solar PV panels is MPPT. The MPPT refers to Maximum Power Point Tracking. A maximum power point (MPPT) is used to track the extreme power from the solar panel and to transfer maximum power from the source to the load. A dc to dc converter which acts as an interface between load and module, for the purpose of transferring maximum power from PV module to the load. By varying the duty cycle of the converter, the load impedance and the source impedance is varied and matched at the peak power point so as to transfer the maximum power. Normally, the MPPT efficiency of the converter is 93-97\%. The MPPT can be used for all climatic and environmental conditions [8]. The comparative study proves that Incremental Conductance (INC) algorithm and Perturb and Observe (P\&O) algorithm techniques are the two most popular algorithms analysed for tracking maximum power form the PV panels. The two different converters such as buck and boost converter are also used for comparative review for employing the 
above-mentioned algorithm. The voltage, current and power output of the PV system for each different combination has been recorded. The performance evaluation on energy point is analysed using MATLAB simulink tools [9].

The above Figure 7 shows the simple diagrammatic representation of MPPT algorithm technique. The Perturb and Observe algorithm has occupies more favorable position than INC as it can decide when the MPPT has come to the MPP, where P\&O wavers around the MPP [9]. Likewise, the incremental conductance can also track quickly based on expanding and diminishing irradiance conditions with higher exactness. The disadvantages of the Perturb and Observe technique is the peak control tracking under quick differing environmental condition is overcome by INC strategy. In Incremental Conductance algorithm, it stops perturbing at the operating point when the MPPT has reached the MPP (Maximum Power Point). The Incremental Conductance algorithm is more complex when compared to P\&O. Figure 8 shows comparis on of buck and boost converter.

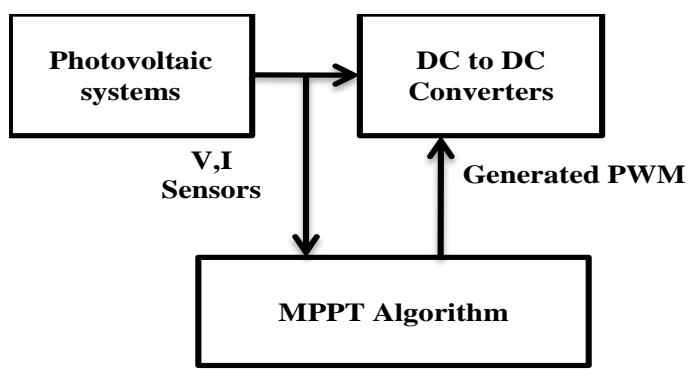

Figure 7. MPPT algorithm configuration techniques

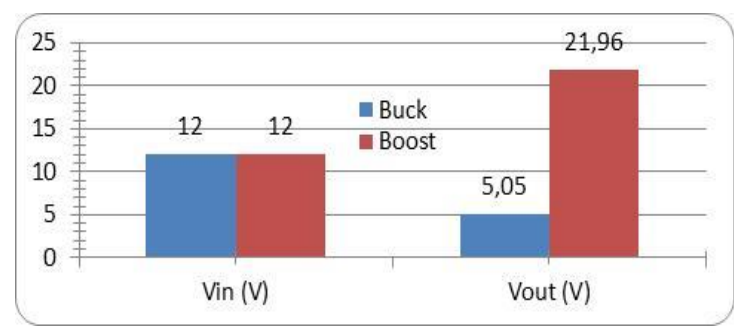

Figure 8. Comparison of buck and boost converter

The above graph shows the different converter topology with their simulation and theoretical results. The input voltage of 10 volt is boosted to $12 \mathrm{~V}$ and reduced to $5 \mathrm{~V}$ using buck operation. This happens by varying the duty cycle of the power converters.

The comparisons of perturb and observe (P\&O) and incremental conductance (IC) algorithm for buck converter and boost converter are described in Figure 9 and 10 and shows that output accuracy is greater for IC compared to P\&O. But the simplest and feasible way to use MPPT algorithm is P\&O. In the boost converter, highest output for boost converter is achieved by using the $\mathrm{P} \& \mathrm{O}$.

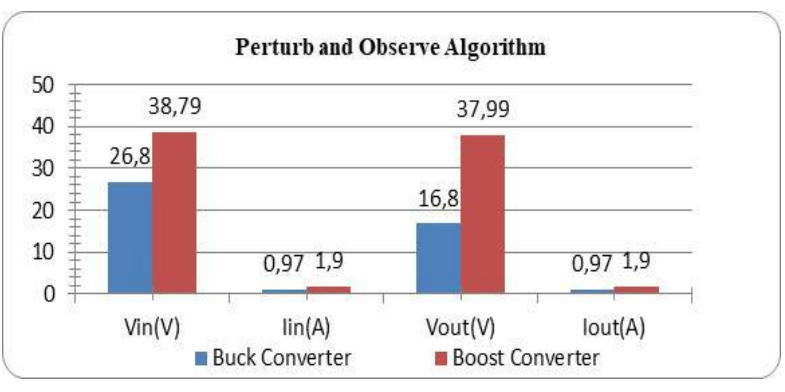

Figure 9. Comparis on of buck and boost converter with $\mathrm{P} \& \mathrm{O}$

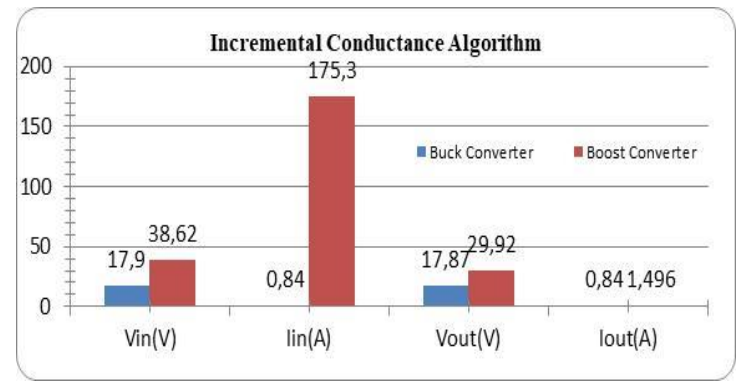

Figure 10. Comparis on of buck and boost converter with INC

Generally, the current and voltage from the PV panel are fed as an input to these algorithms and then based on the power and voltage of the PV system, the duty cycle of the converter varies according to the design. The converters are simulated for various temperature with constant irradiation and constant load. Two MPPT algorithms are applied on these converters to check its performance on various temperature. The simulated value is shown in Table 2 and 3. 
Table 2. Buck Converter Simulated for Various Temperature

\begin{tabular}{ccccccc}
\hline Irradiance & Temperature & Load & \multicolumn{2}{c}{ Input voltage (V) } & \multicolumn{2}{c}{ Output voltage (V) } \\
\cline { 4 - 7 } $\mathrm{W} / \mathrm{m}^{2}$ & ${ }^{\circ} \mathrm{C}$ & $\Omega$ & $\mathrm{P} \& \mathrm{O}$ & $\mathrm{IC}$ & $\mathrm{P} \& \mathrm{O}$ & IC \\
\hline \multirow{4}{*}{1000} & 40 & & 56 & 56.63 & 49.95 & 47.19 \\
& 35 & & 57.11 & 57.48 & 50.11 & 47.91 \\
& 30 & 100 & 58.28 & 58.32 & 50.47 & 48.62 \\
& 25 & & 59.17 & 59.16 & 52.72 & 49.34 \\
& 20 & & 60.96 & 60.01 & 52.98 & 50.05 \\
\hline
\end{tabular}

Table 3. Boost Converter Simulated for Various Temperature

\begin{tabular}{ccccccc}
\hline Irradiance & Temperature & Load & \multicolumn{2}{c}{ Input voltage $(\mathrm{V})$} & \multicolumn{2}{c}{ Output voltage (V) } \\
\cline { 4 - 6 } $\mathrm{W} / \mathrm{m}^{2}$ & ${ }^{\circ} \mathrm{C}$ & $\Omega$ & $\mathrm{P} \& \mathrm{O}$ & $\mathrm{IC}$ & $\mathrm{P} \& \mathrm{O}$ & $\mathrm{IC}$ \\
\hline \multirow{4}{*}{1000} & 40 & & 55.47 & 51.65 & 98.61 & 141.9 \\
& 35 & & 55.6 & 53.15 & 115 & 141.3 \\
& 30 & \multirow{2}{*}{100} & 55.79 & 53.74 & 126.61 & 143.6 \\
& 25 & & 55.08 & 53.41 & 135.7 & 144 \\
& 20 & & 55.19 & 54.22 & 142 & 144.3 \\
\hline
\end{tabular}

\section{CLOSED LOOP CONTROL OF CONVERTERS}

From the previous section, it is observed that there is lot variation in output voltage since it is operated in open loop mode. Because of the low output voltage of PV system, the high productive DC to DC converters are significantly used for renewable power applications. To overcome these problems there are various control techniques used in combination with these converters. The closed loop control mechanis $m$ is used to achieve better power factor with good response and increased efficiency. The design of closed loop control is achieved using this block diagram shown in Figure 11.

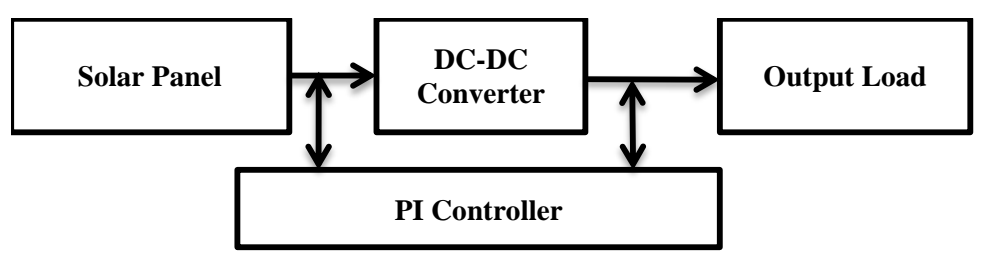

Figure 11. Block diagram of closed loop control for converters

The closed loop system is able to maintain constant output voltage [12-14]. This type of different converter provides good output voltage regulation for all converter design. Thus, the boost converter is also capable of improving the voltage level from $15 \mathrm{~V}$ to the required level. This shows the constant voltage can be achieved using closed loop control. The closed loop control system is required to achieve the desired output with improved accuracy. In the Table 4 the comparisons of boost converter for open loop and closed loop techniques is analyzed. From this table it is understood that the output voltage is cons tant for the closed loop control mechanism.

Table 4. Comparison between Closed and Open Loop Boost Converter

\begin{tabular}{ccc}
\hline Parameter & Open loop voltage control & Closed loop volt age control \\
& $(\mathrm{V})$ & $(\mathrm{V})$ \\
\hline $\mathrm{V}_{\text {in }}(\mathrm{V})$ & 15 & 15 \\
$\mathrm{~V}_{\text {out }}(\mathrm{V})$ & 56 & 48 \\
& (varying voltage) & (constant voltage) \\
\hline
\end{tabular}

The PID controller uses the values such as $\mathrm{Kp}, \mathrm{Ki}, \mathrm{Kd}$ for efficient control of any converter. These values can be determined by using various algorithms namely particle swarm optimization, looping method and generic algorithm etc. Kp is used to adjust the peak overshoot of the output waveform. Ki is used to set the settling time of the system. Kd is used to decide the rise time of the system. But it is most difficult to calculate those values because they require more complexity in design. In this manner, compensator transfer function is inferred by various control techniques and looked at in view of steady state response and system 
response characteristics. This exertion investigates which strategy will be the best for ordinary DC-DC support converter topology.

The different techniques used are shown in the table below. It explains the different system characteristics by employing different values for $\mathrm{Kp}, \mathrm{Ki}, \mathrm{Kd}$. The tuning of system characteristics is to achieve the highest value of output with constant voltage. There are different methods for the tuning methods. Few of the methods are analyzed and the values are determined. The value for these systems is difficult to predict after solving for equations. These techniques will reduce errors by automatically adjusting the systems input in the system and improves the stability of the unstable system. The various system characteristics with different tuning techniques are compared in the Table 5.

Table 5. Comparis on of System Characteristics

\begin{tabular}{cccc}
\hline Tuning Method & $\begin{array}{c}\text { \%Peak } \\
\text { Overshoot }(\%)\end{array}$ & $\begin{array}{c}\text { Settling } \\
\text { Time }(\mathrm{s})\end{array}$ & $\begin{array}{c}\text { Rise Time } \\
(\mathrm{s})\end{array}$ \\
\hline Zeigler-Nichols & 39.2 & 0.00205 & $2.38 \times 10^{-5}$ \\
Chein-Hrones-Reswick & 27.6 & 0.00189 & $3.04 \times 10^{-5}$ \\
Approximate MIGO & 10.8 & 0.00166 & 0.000184 \\
Loop & 8.72 & $7.85 \times 10^{-6}$ & $1.76 \times 10^{-6}$ \\
shaping & & & \\
\hline
\end{tabular}

The paralleling of closed loop boost converters with signal conditioning block, using any of the above-mentioned algorithms [15] can also be employed for closed loop control. The alternate investigation and design consideration of DC to DC boost converter utilizing PID control mechanism for photovoltaic high voltage applications is proposed.

The effectiveness of this technique achieved under load condition was more than $90 \%$. This type of converter topology may be satisfactory for high voltage and high-power application. Thus, the converter has the delicate exchanging of the power between the source and the load with minimum number of device, soft switching of the switch, high voltage and power output. But there is a problem in using the power electronic switches as it introduces harmonics in the system. It is better to analyse the power quality at the required instant for better efficiency. The simulation result shows that the output is increased to higher level as shown in the Table 6.

Table 6. Simulation Results of Boost Converter

\begin{tabular}{cc}
\hline Parameter & Voltage (V) \\
\hline $\mathrm{V}_{\text {in }}$ & 17.1 \\
$\mathrm{~V}_{\text {out }}$ & 317 \\
\hline
\end{tabular}

\section{CONCLUSION}

Thus, the photovoltaic system output is enhanced using the power conversion topologies. The different DC to DC converter topologies are compared and analyzed with their output voltage, current and power and their efficiencies are analyzed. The controller is designed based on the equations obtained from the analysis of converters in their steady state and transient state. The ON and OFF time period of the switch used in the boost converter is determined by the MPPT technique to track the maximum efficiency. The converter employed with switches, obtain their duty ratio based on the algorithm performing. Two different algorithms are discussed with their advantages and disadvantages. To obtain the constant voltage it is necessary to have a closed loop control technique such as PID controller. Thus, the closed loop control is used to achieve the maximum output with constant magnitude and paralleling of PV system can also be done based on the design requirement. This type of analysis is best applicable for design and installation of rooftop solar PV application.

\section{REFERENCES}

[1] Tjukup Marnoto, Kamaruzzaman Sopian, Wan Ramli Wan Daud, Mohamad Algoul, Azami Zaharim. Mathematical Model for Determining the Performance Characteristics of Multi-Crvstalline Photovoltaic Modules. Proceedings of $9^{\text {th }}$ WSEAS Conference on Mathematical and Computational Methods in Science and Engineering. Trinidad and Tobago. 2007; 79-85.

[2] Sara MacAlpine, Chris Deline, Robert Erickson, Michael Brandemuehl. Module Mismatch Loss and Recoverable Power in Unshaded PV Installations. Proceedings of $38^{\text {th }}$ IEEE Photovoltaic Specialists Conference. USA. 2012; 1388-1392. 
[3] M.C. Alonso-Garciaa, J.M. Ruizb, W. Herrmann. Computer simulation of shading effects in photovoltaic arrays. Renewable Energy. 2006; 31(12): 1986-1993.

[4] Ricardo Orduz, Jorge Solorzano, Miguel Angel Egido, Eduardo Roman. Analytical study and evaluation results of power optimizers for distributed power conditioning in photovoltaic array. Progress in Photovoltaics: Research and Applications. 2013; 21(2): 359-373.

[5] Jorge Solorzano-Moral, Daniel Masa-Bote, Miguel Angel, Egido-Aguilera, Estefania Caamano-Martín. A model for the simulation of energy gains when using distributed maximum power point tracking (DMPPT) in photovoltaic arrays. Progress in Photovoltaics: Research and Applications. 2015; 23: 182-193.

[6] Premkumar, M., Dhanasekar, N., Dhivakar, R., Arunkumar, P. Comparison of MPPT Algorithms for PV System Based DC-DC Converter. Advances in Natural and Applied Sciences. 2016; 17(9): 212-221.

[7] Jaypalsinh Chauhan, Parin Chauhan, Tejas Maniar, Ashish Joshi. Comparison of MPPT Algorithms for DC-DC Converters Based Photovoltaic Systems. International Conference on Energy Efficient Technologies for Sustainability. India. 2013; 476- 481.

[8] Jacob James Nedumgatt, Jay akrishnan. Perturb and Observe MPPT Algorithm for Solar PV Systems-Modeling and Simulation. Annual IEEE India Conference (INDICON). Hy derabad, India. 2011; 523-532.

[9] Premkumar, M., Sumithira, T.R., Sowmya, R. Modelling and Implementation of Cascaded Multilevel Inverter as Solar PV Based Microinverter Using FPGA. International Journal of Intelligent Engineering and Systems. 2018; 11(2): 18-27.

[10] Premkumar M., Jeevanantham R, Muthuvigneshkumar S. Single Phase Module Integrated Converter Topology for Microgrid Network. International Journal of Innovative Research in Electrical, Electronics, Instrumentation and Control Engineering. 2014; 2(3): 1322-1325.

[11] D. P. Hohm, M. E. Ropp. Comparative Study of Maximum Power Point Tracking Algorithms. Progress in Photovoltaics: Research and Applications. 2003; 11(1): 47-63.

[12] Bulent, B., Murat, A. A current-based simple analog MPPT circuit for PV systems. Turkish Journal of Electrical Engineering and Computer Sciences. 2016; 24(4): 3621-3637.

[13] Nor Hanisah Baharudin, Tunku Muhammad Nizar Tunku Mansur, Fairuz Abdul Hamid, Rosnazri Ali, Muhammad Irwanto Misrun. Topologies of DC-DC Converter in Solar PV Applications. Indonesian Journal of Electrical Engineering and Computer Science. 2017; 8(2): 368-374.

[14] Athimulam Kalirasu, Subharensu Sekar Dash. Simulation of Closed Loop Controlled Boost Converter for Solar Installation. Serbian Journal of Electrical Engineering. 2010; 7(1): 121- 130.

[15] Rozana Alik, Awang Jusoh, Nur Ameda Shukri. An Improved Perturb and Observe Checking Algorithm MPPT for Photovoltaic System under Partial Shading Condition. IEEE Conference on Energy Conversion (CENCON). Malaysia. 2015; $4799-8598$.

[16] Rajesh Thumma, Veera Venkata Subrahmanya Kumar Bhajana, Pramod Kumar Aylapogu. Design and Simulation of a New ZVT Bi-directional DC-DC Converter for Electric Vehicles. Indonesian Journal of Electrical Engineering and Computer Science. 2017; 7(1): 75-83. 